\title{
Masculinidades críticas e a proposição analítica e relacional nas contemporâneas discussões de gênero
}

\author{
Homem não tece a dor: queixas e \\ perplexidades masculinas. \\ BENTO, Berenice. \\ Natal: EDUFRN, 2012. 220 p. \\ (c) (1) Esta obra tem licença Creative Commons.
}

A obra apresenta a pesquisa de mestrado construída pela socióloga Berenice Bento e defendida em 1998 no Programa de Pós-Graduação em Sociologia da Universidade de Brasília. A pesquisa entrevistou homens e mulheres da classe média urbana e objetivou refletir sobre a identidade de gênero dos homens à luz das transformações sociais ocorridas nas últimas décadas. Os resultados da pesquisa apontaram a vivência de um tipo específico de masculinidade, a masculinidade crítica, e suscitaram a proposição de novas possibilidades de abordagem do masculino sob referências relacionais e analíticas da questão de gênero.

A autora do livro, Berenice Bento, é graduada em Ciências Sociais pela Universidade Federa de Goiás, mestre em Sociologia pela Universidade de Brasília e doutora em Sociologia pela Universidade de Brasília/Universitat de Barcelona. Bolsista de produtividade em pesquisa do CNPq professora adjunta III na Universidade Federal do Rio Grande do Norte e coordenadora do Núcleo Interdisciplinar Tirésias/UFRN, atua e possui experiências na área de Sociologia e Antropologia, principalmente em questões como: gênero, transexualidade, sexualidade, direitos humanos e estudos queer. É autora, ainda, dos livros $A$ reinvenção do corpo: gênero e sexualidade na experiência transexual (Garamond, 2006) e O que é transexualidade (Coleção Primeiros Passos/Brasiliense,2008).

O livro apresenta a pesquisa sociológica, discute o tema da masculinidade a partir de uma reflexão analítica sobre gênero, produz hipóteses e perspectivas teórico-metodológicas sobre tipos de masculinidades, além de propor a construção de novas possibilidades para a produção de gênero, considerando o panorama histórico mundial e brasileiro acerca dos estudos de gênero e estudos dos homens. A obra distribui-se em seis capítulos e está assim estruturada: "Apresentação", "Introdução", "Metodologia de pesquisa", "Gênero: uma reflexão teórica", "Masculinidade hegemônica e outras masculinidades", "A emergência de uma nova subjetividade?", "Negociação e negação em relações contraditórias", "A ideologia individualista e as relações de gênero" e "Considerações finais".

A proposta do livro constrói-se a partir da introdução, na qual a autora apresenta um levantamento bibliográfico que expõe um panorama mundial e brasileiro dos estudos de gênero e gênero masculino sob uma contextualização de informações que destacam instituições, serviços, fatos, discussões e movimentos voltados aos homens e/ou por eles constituídos. O trabalho orienta-se por questionamentos como: "depois de tantas mudanças e conquistas das mulheres nos últimos trinta anos e tantas outras mudanças que ocorreram nas múltiplas relações sociais, perguntase: como está o homem? O que mudou?" Segundo a autora, a obra pode contribuir com a reflexão das relações de gênero para a compreensão da identidade masculina, buscando pensar relacionalmente a construção das identidades do gênero masculino em suas variadas relações. O trabalho assentou-se em três níveis: a relação entre a subjetividade e sociedade, a relação de gênero e o gênero masculino articulado aos dois primeiros níveis.

No capítulo 1, a autora descreve os detalhes e procedimentos da pesquisa. Além disso, comenta aspectos que sugerem suas orientações teóricas. A pesquisadora entrevistou quinze homens e sete mulheres de classe média urbana e as entrevistas buscaram sondar os motivos que levam os homens a buscarem o consultório de um especialista e saber se o número de procuras dos consultórios pelos homens tem aumentado. Apesar de os entrevistados serem pertencentes aos segmentos intelectualizados e psicologizados, a autora destacou a multiplicidade de realidades que coexistem na classe social que eles constituem. A pesquisadora elenca aspectos sócio-históricos que caracterizam seus entrevistados e ressalta as ideologias individualista e hierárquica como posturas constituintes dos arranjos simbólicos 
expressados pelos entrevistados e que vêm transformando as relações de gênero nos últimos anos. Na referida discussão, Bento menciona, entre outros aspectos da discussão, a difusão da cultura psicanalíitica, os discursos sobre condicionamentos sociais dos entrevistados, a tríade saber-prazer-poder de Foucault' e o acúmulo do capital cultural, ${ }^{2}$ conceitos imprescindíveis à busca da compreensão do fenômeno estudado e seu objeto: as mudanças que estão sendo gestadas na subjetividade dos homens diante das transformações históricas e sociais nas relações de gênero. Além disso, a autora expõe procedimentos, particularidades, dificuldades e desafios encontrados na pesquisa durante seu percurso analítico da questão de gênero.

Adiante, no capítulo 2, o livro aborda a questão de gênero a partir de uma reflexão teórica. O capítulo discute percurso e contexto de surgimento dos estudos de gênero e seu recente e conturbado caminho para o estudo das relações de gênero. Desenvolvendo tal argumentaçấo, a autora questiona obras e autores ${ }^{3}$ de perspectiva universalista sobre as relações de gênero, e em contraponto trata do texto Gênero, uma categoria útil de análise histórica, de $\mathrm{Scott,}{ }^{4}$ para ressaltar a necessidade de novas propostas metodológicas para estudo das relações de gênero. Os estudos da mulher surgiram na década de 70 e, a partir da década de 80 , tais estudos passaram a ser denominados de estudos de gênero.

Bento aponta os estudos de Chodorow ${ }^{5}$ como universalista, devido ao caráter psicanalítico que fundamenta as diferenças de personalidade e de papéis sexuais (buscados nas estruturas mentais inconscientes da personalidade), o que pode desconsiderar os aspectos relacionais, históricos e contextual-situacional. Rosaldo ${ }^{6}$ propõe que as relações de gênero fundamentam-se em relações desiguais de poder em caráter universal e estrutural pelas esferas domésticas e públicas, Bento questiona a autora argumentando que tal generalização das relações de gênero não se ocupa de sociedades e culturas que não desenvolvem tais relações como as descritas e propostas por Rosaldo. A crítica se dá, então, sobre o fato de a epistemologia de gênero necessitar considerar à qual sociedade está se referindo e o que está sendo pesquisado, preocupando-se com generalizações que podem homogeneizar as relações e excluir outras possibilidades. Bento contesta a proposição de Ortner, ${ }^{7}$ pois esta procura explicar a subordinação do gênero feminino ao masculino, sem considerar as sociedades e relações específicas, não mencionadas no estudo de Ortner. Além disso, Bento critica Ortner ao apontar que o estudo de gênero precisa ocupar-se da construção relacional, e não necessariamente focar fenômenos como a subordinação e legitimá-los como fundamento das relações desiguais, o que desconsidera o processo e a agência dos envolvidos. Bento utiliza as argumentações de Scott para abordar uma perspectiva de gênero cada vez mais relacional e analítica. Segundo Scott, a categoria gênero vinculou-se à busca da compreensão epistemológica das relações de gênero, e não necessariamente caracterizado por militância políica. E, ao se propor como uma nova perspectiva metodológica, a categoria de gênero necessitou questionar os paradigmas constituídos até então para compreender a construção das relações sociais. A autora utiliza a concepção de gênero construída por Scott para apontar o caráter analítico e relacional de tal categoria: "o termo 'gênero', segundo a concepção de Scott, sugere que as relações entre os sexos são aspectos primários da organização social, que os termos da identidade masculina e feminina são determinados culturalmente e, ainda, que as diferenças entre os sexos se constituem e são constituídas pelas relações sociais, atravessando-as transversalmente, colocando em mútua relação, em todos os níveis sociais, as diferenças entre os sexos".

No terceiro capítulo, "Masculinidade Hegemônica e outras masculinidades", a autora discute a construção da masculinidade e explana sobre como os estudos dos homens vêm preocupando-se em delinear os processos sociais de construção da masculinidade, relacionando tais processos a contextos sociais específicos. Ela se refere à masculinidade hegemônica apontada por Connell ${ }^{8}$ como uma masculinidade que se impõe sob as outras masculinidades, e discute a masculinidade como uma configuração prática em torno dos homens nas relações de gênero. Ao se referir aos entrevistados por sua pesquisa, Bento os define como "Masculinidades Críticas", caracterizando-os como homens que apresentam uma reflexividade na construção de suas masculinidades. De maneira não generalizante, a autora define a masculinidade crítica na tentativa de agregar a multiplicidade às conceituações de masculinidade. Discutindo a construção das masculinidades nas relações entre as masculinidades e nas demais relações de gênero, a autora discute ainda a relação entre a masculinidade e homofobia, argumentando que, ao passo que a masculinidade trata-se "de um processo de aprovação social masculina", a homofobia funciona como um princípio lógico que fundamenta a definição cultural de masculinidade. 
No capítulo 4: "A emergência de uma nova subjetividade?", Bento busca refletir se as transformações macro ocorridas no Brasil ao longo dos últimos anos mudaram o campo da subjetividade nas dimensões das gerações, família infidelidade masculina, casamento e relações de gênero e na maternidade. Mencionando o processo de urbanização e industrialização do Brasil como processo desenvolvimentista que mobilizou a especialização de mão de obra e a inserção cada vez maior das mulheres no mercado de trabalho, além do ingresso ampliado de pessoas nas universidades, Bento argumenta sobre as transformações ocorridas no Brasil que se traduziram nas relações e subjetividades. Tais mudanças e traduções alteraram valores e referências que se conflitaram nas subjetividades a partir do embate com as concepções tradicionais, o que, consequentemente, agregou-se às relações de gênero e construção de masculinidades, como apresenta a pesquisadora a partir dos discursos de seus entrevistados. Relacionando tais transformações às discussões propostas por Bourdieu, ${ }^{9}$ Foucault, ${ }^{10}$ Nolasco ${ }^{11}$ e Mendes de Almeida, ${ }^{12}$ a autora defende a multiplicidade de masculinidades produzidas pelos processos constituintes das relações de gênero na história, sociedade e cultura.

Abordando a "Negociação e negação em relações contraditórias", o capítulo 5 apresenta as relações construídas pelos entrevistados e discute as ideologias e produções subjetivas que os participantes elaboram na constituição de novas relações de gênero que experimentam junto a seus pares. Na referida discussão, Bento fundamenta-se na concepção relacional do poder proposta por Foucault para incluir a noção de poder na relação de gênero, menciona as argumentações de Giddens, ${ }^{13}$ para referir-se ao relacionamento igualitário, discute o diálogo, bem como as regras silenciosas da relação e fecha o raciocínio acerca das relações, sobre o que fo produzido em sua pesquisa, discutindo a inversão na representação dos gêneros. Tais argumentações foram apresentadas pela autora como dimensões complexas características das relações e que constituem as masculinidades múltiplas. Bento destaca que a utilização de generalizações e a desconsideração de contextos específicos não compõem a proposta do processo analíitico e relacional dos estudos de gênero que está se constituindo.

Ao discutir a ideologia individualista e as relações de gênero, a autora, no capítulo 6 , expõe que "a liberação feminina e a emergência da ideologia individualista se articulam em graus e formas diferenciadas para propiciar o questionamento da identidade de gênero gestada na socialização primária". Desta feita, a insurgência de uma nova maneira de organização da subjetividade e de estruturação das relações de gênero tem-se dado pela confluência da liberação feminina e a ideologia individualista, o que vem mobilizando conflitos nas subjetividades e nas relações, pois se defrontam com a tradicional ideologia hierárquica que, por muito tempo (e ainda hoje persiste), baseou as relações de gênero e a construção social das perfomances masculinas e femininas.

Em suas considerações finais, a autora destaca que o seu trabalho não visou generalizações mas a emergência analítica de tipos de masculinidade que não se identificam com a masculinidade hegemônica. Além disso, propôs a "desconstrução analítica de representação substantiva do 'masculino'" para construção de novas perspectivas teórico-metodológicas que abordem relacionalmente a categoria analítica de gênero a partir de instrumentos conceituais fundamentados na pesquisa empírica. A obra empenhou-se em contribuir com as discussões orientadas para a reflexão de problemáticas sociais sobre gênero e masculinidade, visto que se necessita ainda de um amadurecimento sociológico para a busca de compreensão de tais fenômenos.

A obra caracteriza-se como uma produção que pode basear as contemporâneas necessidades científicas de discutir-se a questão de gênero e fomenta novas possibilidades de discutir gênero sob perspectivas cada vez mais analíticas e relacionais.

O livro apresenta discussões sobre a construção relacional das identidades de gênero masculino e contribui positivamente para a atual produção brasileira de gênero que historicamente vem sendo delineada pelos estudos feministas, e que pode ser potencializada pelos estudos das relações de gênero por perspectivas cada vez mais interdisciplinares e epistemologicamente mais relacionais. Um aspecto que poderia somar a discussão proposta pela autora seria a ética das relações como dinâmica processual das negociações de gênero que estruturam e fazem a manutenção das relações. A obra é inovadora ao propor à produção acadêmica do país novas possibilidades de discutir-se gênero como categoria analítica e relacional, distanciando-se dos argumentos orientados somente pela hierarquização, polarização e oposicionismo.

\section{Notas}

'Michael FOUCAULT, 1985.

${ }^{2}$ Pierre BOURDIEU, 1989. 
${ }^{3} \mathrm{~A}$ autora discute as obras: Estrutura Familiar e personalidade feminina (CHODOROW, 1979), Está a mulher para o homem como a natureza para a cultura? (ORTNER, 1979) $\mathrm{e}$ A mulher, a cultura e a sociedade, uma revisão teórica (ROSALDO, 1979).

${ }^{4}$ Joan SCOT, 1995.

${ }^{5}$ Nancy Chodorow, 1979

${ }^{6}$ Michelle Zimbalist ROSALDO, 1979

${ }^{7}$ Sherry ORTNER, 1979.

${ }^{8}$ Robert W. CONNELL, 1987

${ }^{9}$ Pierre BOURDIEU, 1983

${ }^{10}$ Michael FOUCAULT, 1993

$"$ Sócrates NOLASCO, 1995.

${ }^{12}$ Maria Isabel Mendes de ALMEIDA, 1987.

${ }^{13}$ Anthony GIDDENS, 1992.

\section{Referências}

BOURDIEU, Pierre. "Uma ciência que perturba". In: Questões de Sociologia. Rio de Janeiro: Marco Zero, 1983.

"Algumas propriedades dos campos". In: Questões de Sociologia. Rio de Janeiro:

Marco Zero, 1983. p. 89-94.

"A gênese dos conceitos de habitus e de

Campo". In:

O Poder Simbólico. Rio de Janeiro: DIFEL, 1989. p. 59-73.

"A identidade e a representação". In O Poder Simbólico. Rio de Janeiro:

DIFEL, 1989. p. 163-208. p. 107-132.

. "A representação política: elementos para

uma teoria do campo político". In: . $\mathrm{O}$

Poder Simbólico. Rio de Janeiro: DIFEL, 1989. p. 163-208.

CHODOROW, Nancy. "Estrutura familiar e personalidade feminine". In: ROSALDO, M. Z.; LAMPHERE,
L. (Orgs.). A mulher, a cultura e a sociedade. Rio de Janeiro: Paz e Terra, 1979. p. 65-94.

CONNELL, Robert William. Masculinities. Berkeley: University of Califórnia Press, 1987.

FOUCAULT, Michel. História da Sexualidade. Rio de Janeiro: Graal, 1985. v.1.

Microfísica do poder. Rio de Janeiro: Graal, 1993

GIDDENS, Anthony. A transformação da intimidade: sexualidade, amor e erotismo nas sociedades modernas. São Paulo: Editora da Universidade Estadual Paulista, 1992.

MENDES DE ALMEIDA, Maria Izabel. A modernização da maternidade (1950-1980): uma abordagem sociológica da subjetividade na família de classe média brasileira. Dissertação (Mestrado em Sociologia) - UPERJ, Rio de Janeiro, 1987

NOLASCO, S. (Org.). A desconstrução do masculino. Rio de Janeiro: Rocco, 1995.

ORTNER, S. "Está a Mulher para o homem assim como a natureza para a cultura?". In ROSALDO, M. Z.; LAMPHERE, L. (Orgs.). A mulher, a cultura e a sociedade. Rio de Janeiro: Paz e Terra, 1979. p. 95-120.

ROSALDO, M.Z.; LAMPHERE, L. (Orgs.). A mulher, a cultura e a sociedade. Rio de Janeiro: Paz e Terra, 1979.

SCOT, J. "Gênero: umacategoriaútil de análise histórica". Revista Educação e Realidade, Porto Alegre, v. 20, n.2, p. 133-184, jul./dez. 1995.

Fabiane Aguiar Silva Universidade Federal do Amazonas 